\title{
Editorial
}

\section{Alison Gilmore}

When I was corresponding with one of the authors in this issue, Emeritus Professor James Popham, I received an advertisement for his latest book in a document called "Popham eflyer". As educationalists are wont to be, particularly those in assessment and evaluation research, I am at times somewhat distracted by the swirling notions of effect sizes in educational research. Consequently, I misread the name of the file as "Popham effect". Effect size is a statistic that gives an estimate of the magnitude of a difference.

Having read "Popham effect", I immediately pondered the magnitude of the difference that Professor Popham has made to assessment matters (and instructional and evaluation matters) over a career of more than 50 years. As education assessment specialists, researchers and practitioners would attest (and as is evident in a number of articles in this issue of Assessment Matters, where authors refer to his work), his contribution and influence have been substantial. It is therefore a great honour that Professor Popham has agreed to write for Assessment Matters.

This, the second issue of Assessment Matters, addresses a number of topics that span the complexity and nature of assessment discourse and assessment for learning, the importance of developing teacher and student assessment capabilities and participation, through to assessment of learning as conducted through the National Certificate of Educational Achievement (NCEA) and the Premier Scholarship examinations in New Zealand.

Kari Smith of Norway examines the assessment discourse in that country, but her discussion could equally be located anywhere. Not only is assessment a complex concept, it is also a complex activity, and Professor Smith reports that in Norway there is mixed understanding of key assessment-related terms (such as "assessment", "measurement/ testing" and "evaluation") and the complex pedagogical actions they 
represent. She describes assessment as a "complex process that requires a high level of professional knowledge about assessment owned by those who make the decisions, including teachers" and as "the tapestry of decisions [that] are consciously made and put together by the teacher". However, the opportunity for teachers to be challenged by assessment as a complex activity, and to develop their assessment capability, can be undermined when they are issued with detailed instructions on how to practise assessment.

Relatively little research has been done to inform preservice teacher education in assessment, although the work of DeLuca, Klinger, Searle, and Shulha begins to shed light on how graduate preservice programmes might address the need to develop assessment knowledge and skills in teachers. They document the model of assessment education that is evolving at Queens University, Canada, which aims to introduce preservice teachers to contemporary classroom assessment issues and practices. A central focus of the programme is to develop students' skills to engage in continued professional learning (in assessment) throughout their teaching careers.

Mary Hill, Bronwen Cowie, Alison Gilmore, and Lisa Smith, from four New Zealand universities, explore assessment education for students enrolled in three-year undergraduate primary and early childhood teacher education. The authors seek to explore how their four tertiary institutions have developed preservice teachers' assessment capability within their teacher education programmes while simultaneously creating a national professional network of assessment teacher educators.

As the previous authors contend, Jill Willis argues that although assessment for learning is an appealingly simple concept, it is surprisingly difficult to realise in practice. Willis uses a sociocultural theory of learning to investigate assessment for learning as it is practised in three classrooms. She argues that assessment for learning is:

pedagogical practice as it occurs within the daily interactions in the classroom and enables the teacher and students to negotiate shared understandings of productive and more expert ways of participating in the learning that is valued in the classroom community of practice. 
Thus, assessment for learning practices can be understood as a form of "guided participation as learners are apprenticed towards autonomy" within a community of practice with a "shared repertoire, mutual engagement and a joint enterprise".

Craig Steed and Jenny Poskitt also explore the importance of the classroom environment-in particular, student, teacher, peer and classroom culture-for supporting students' learning. The authors argue that student-generated questions (adaptive help seeking) provide rich opportunities for interactive formative assessment to occur in the classroom, provide a basis of supporting assessment for learning and develop students' self-regulation and hence autonomy.

Many countries are experiencing national curriculum and assessment reforms involving the implementation of national standards of expected student achievement and progress. However, the political agenda for improvement through accountability is in tension with an educational agenda of supporting students' learning. Val Klenowski and Claire Wyatt-Smith of Australia review the role and purpose of standards in the context of these reforms. They argue that teacher judgements and informed interpretations of assessment data are central to gaining greater coherence between these two agendas. Moderation activities provide opportunities for teachers, as assessors, to develop and articulate their understanding of the standards as used in the assessment of student work. Through such talk, and the classification of the work against the standards, teacher judgements become "tuned in" or aligned to the standards, and high levels of reliability in teacher judgements can be achieved.

Shifting to a New Zealand focus, assessment for NCEA is standards-based. James Graham, Luanna Meyer, Lynanne McKenzie, John McClure, and Kirsty Weir argue that it incorporates enhanced flexibility, student choice and grading practices independent of comparisons with others-features potentially more amenable to Māori and Pacific cultures. In theory, NCEA has the potential to support achievement by all students in a manner that is culturally responsive to core values held by Pacific people and Māori. As a standards-based assessment system, NCEA can be a springboard for collective accomplishment and pride that neither overshadows individual accomplishments nor requires individuals to fail. The authors explore the 
views of Māori and Pacific students and parents about NCEA and its impact on educational aspirations.

Finally, Michael Johnston examines the Premier New Zealand Scholarship, which is awarded annually to students performing at a high level in multiple secondary school subjects. Historically the award has been dominated by students with successful results in mathematics and the sciences. Johnston investigates the relative representation of various types of subjects in the Premier awards over several years and examines possible reasons for this dominance in terms of students' choice of subjects and student ability.

Popham, in his commentary, likens the complexity and challenge of adopting assessment for learning practices to mastering a 21 st century electric toothbrush. In his experience, there are similar levels of complexity and intimidation. Using assessment for learning successfully requires teachers to be assessment capable, and developing teachers' assessment capability has implications for both preservice teacher education and inservice teacher professional learning. Preservice teacher education programmes can be constrained by the amount of instructional time available, along with decisions about what is an appropriate assessment curriculum and how it should be delivered. Given these constraints, it is unlikely that student teachers will complete their programme with a robust and comprehensive understanding of assessment practice, theory and philosophy. Popham therefore proposes developing a formative assessment starter kit (or FASK) as a way to allow inservice teachers to experience formative assessment within the classroom and therefore overcome the intimidation posed by its complexity.

A number of papers in this issue focus on developing teachers' assessment capabilities. During 6-8 May 2010, the Assessment and Evaluation Group, Faculty of Education, Queen's University, Kingston, Canada, hosted an international symposium on classroom assessment entitled "Preparing Teachers for Roles and Challenges in Assessment: An International Investigation". Professor Lyn Shulha, along with her colleagues at Queen's University who have written for Assessment Matters in the first two issues, led the symposium. 
Representatives from New Zealand, Australia, Scotland and Canada presented current research and national initiatives in developing teachers' assessment capabilities. The opportunities and challenges of preparing teachers for their assessment roles and responsibilities were discussed within national and international contexts. The symposium website http://orgs.educ.queensu.ca/aeg/symposium/index.html outlines the programme and participants of the symposium, and will in time also include a summary document outlining the issues discussed and decisions made. The symposium provided an excellent opportunity to discuss research indepth and to consider international perspectives related to the work of each team. The members of the symposium will continue to meet biennially to advance a common agenda of developing teachers' assessment capabilities_an issue of high priority in all four countries represented.

Alison Gilmore

Managing Editor 